DOE-STD-3020-97

January 1997

Supersedes DOE NE F3-45

January 1987

DOE STANDARD

\title{
SPECIFICATION FOR HEPA FILTERS USED BY DOE CONTRACTORS
}

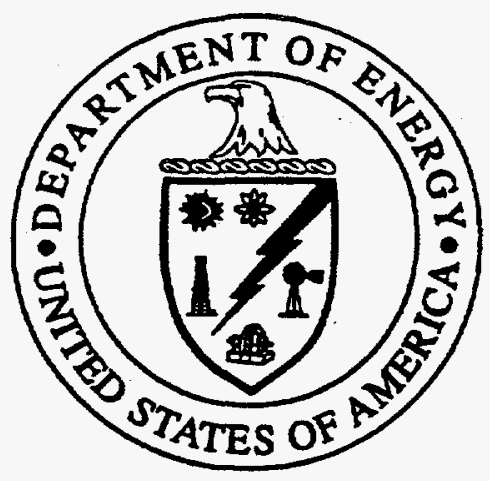

U.S. Department of Energy

FSC 6910 Washington, D.C. 20585

DISTRIBUTION STATEMENT A. Approved for public release; distribution is unlimited.

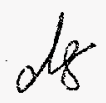


This document has been reproduced directly from the best available copy.

Available to DOE and DOE contractors from the Office of Scientific and Technical Information, P.O. Box 62, Oak Ridge, TN 37831; (423) 576-8401.

Available to the public from the U.S. Department of Commerce, Technology Administration, National Technical Information Service, Springfield, VA 22161; (703) $487-4650$.

Order No. DE97000782 


\section{DISCLAIMIER}

Portions of this document may be illegible in electronic image products. Images are produced from the best available original document. 


\section{FOREWARD}

This Department of Energy standard supersedes DOE NE F3-45 and is approved for use by all DOE components and their contractors.

This standard was developed primarily for application in U.S. Department of Energy programs. It provides guidance to DOE contractor sites for procurement and testing of High Efficiency Particulate Air (HEPA) filters used in DOE nuclear facilities. This standard was designed to achieve a technical coordination among individuals of recognized authority from affected DOE programs, including manufacturers, purchasers, users, and technical experts. This procedure utilized a writing group to prepare the standard and a technical review committee to provide formal review and comment.

Beneficial comments (recommendations, additions, deletions) and any pertinent data that may improve this document should be sent to the Office of Nuclear Safety Policy and Standards (EH-31), U.S. Department of Energy, Washington, D.C. 20585, by letter or by using the self-addressed Document Improvement Proposal form (DOE F 1300.3) appearing at the end of this document.

DOE technical standards, such as this standard, do not establish requirements. However, all or part of the provisions in a DOE standard can become requirements under the following circumstances:

(1) they are explicitly stated to be requirements in a DOE requirements document; or

(2) the organization makes a commitment to meet a standard in a contract or in an implementation plan or program plan required by a DOE requirements document.

Throughout this standard, the word "shall" is used to denote actions that must be performed if the objectives of this standard are to be met. If the provisions in this standard are made requirements through one of the two ways discussed above, then the "shall" statements would become requirements. It is not appropriate to consider that "should" statements would automatically be converted to "shall" statements as this action would violate the consensus process used to approve this standard. 
DOE-STD-3020-97

Intentionally Blank 
TABLE OF CONTENTS

PARAGRAPH

PAGE

FOREWORD . iii

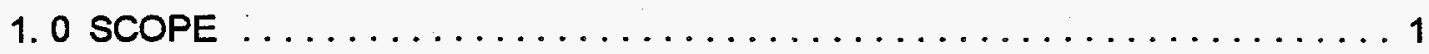

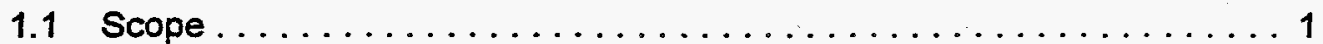

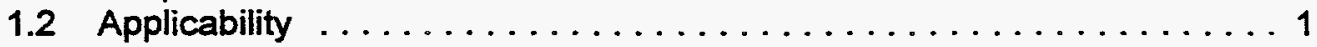

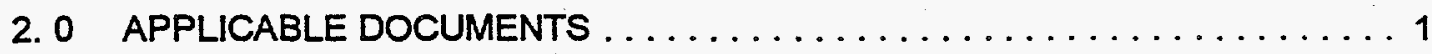

2.1 Department of Energy (DOE) Standards $\ldots \ldots \ldots \ldots \ldots \ldots \ldots \ldots$

2.2 Department of Defense Military Standards (MIL) . . . . . . . . . 2

2.3 National Consensus Standards ..................... 2

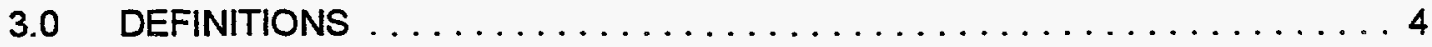

4.0 GENERAL REQUIREMENTS $\ldots \ldots \ldots \ldots \ldots \ldots \ldots \ldots \ldots \ldots \ldots \ldots \ldots \ldots \ldots$

5.0 HEPA FILTER PROCUREMENT $\ldots \ldots \ldots \ldots \ldots \ldots \ldots \ldots \ldots$

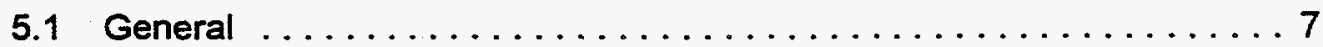

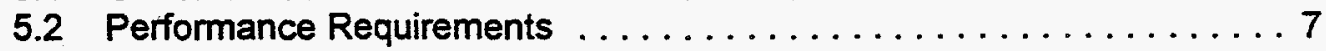

5.3 Materials Requirements .................... 9

5.4 Filter Construction . . . . . . . . . . . . . . . . . 12

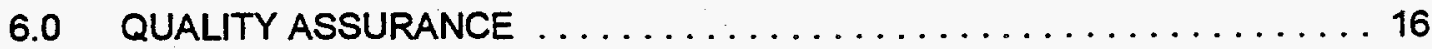

6.1 Manufacturers' Quality Assurance Program, Procedures,

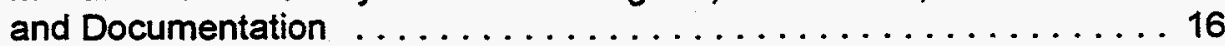

6.2 DOE Production Testing and Marking . . . . . . . . . . . 18

7.0 PACKAGING, SHIPPING, AND STORAGE $\ldots \ldots \ldots \ldots \ldots \ldots \ldots$

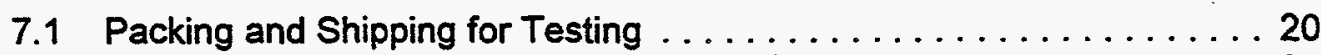

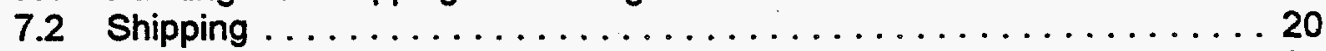

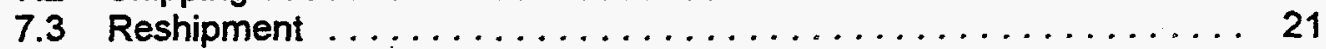

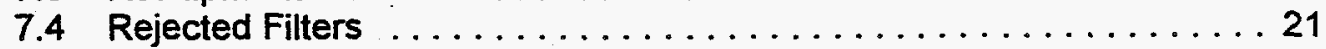


DOE-STD-3020-97

Intentionally Blank 


\section{DOE-STD-3020-97}

\subsection{SCOPE}

\subsection{Scope}

This standard establishes specification and testing requirements for High Efficiency Particulate Air (HEPA) filters procured to provide personnel and environmental protection when installed in DOE nuclear facilities. The standard specifies minimum requirements to be included in contractor specifications.

\subsection{Applicability}

This Standard applies to procurement of HEPA filters to be installed in DOE nuclear facilities.

\subsection{APPLICABLE DOCUMENTS}

The following documents are either a part of this standard to the extent specified herein, or specify materials of HEPA filter construction. Unless otherwise stated, the current issue date and revision number of a referenced document shall apply, including addenda and/or amendments. In the event of a conflict between provisions of this standard and provisions of the referenced documents, the text of this standard shall take precedence. Appeals in this matter may be addressed to the DOE "Preparing Activity" (DP-45), which is designated as the DOE entity responsible for issue and interpretation of this standard.

\subsection{Department of Energy (DOE) Standards}

DOE F 3-42 - Operating Policy of DOE Filter Test Program DOE F 3-43 - Quality Assurance Testing of HEPA Filters DOE F 3-44 - DOE Filter Test Facility Quality Program Plan Note: The above standards are currently under revision. At their issuance, their designator will be modified to conform with the latest DOE guidelines. Subsequently, their designator in this standard will be updated through a page change modification. 


\section{DOE-STD-3020-97}

\subsection{Department of Defense Military Standards (MIL)}

MIL-STD-105E - Sampling Procedures and Tables for Inspection by Attributes

MIL-STD-282- Filter Units, Protective Clothing, Gas Mask Components and Related Products: Performance Test Method

MIL-F-51079 - Filter Medium, Fire Resistant, High Efficiency

MIL-S-8660C - Silicone Compound, NATO Code Number S-726

\subsection{National Consensus Standards}

\subsubsection{American Society For Testing and Materials (ASTM)}

ASTM A 176 - A Specification for Stainless and Heat-Resisting Chromium Steel Plate, Sheet and Strip

ASTM A 240 - A Specification for Heat-Resisting Chromium and ChromiumNickel Stainless Steel Plate, Sheet, and Strip ASTM A 366/A 366M - Standard Specification for Steel, Sheet, Carbon,

Cold-Rolled, Commercial Quality

ASTM A 570/570M - Specification for Steel, Sheet, and Strip, for Carbon, Hot

Rolled, Structural Quality

ASTM A 611 - Specification for Steel, Cold-Rolled Sheet, Carbon, Hot

Rolled, Structural Quality

ASTM A 740 - Specification for Hardware Cloth (Woven or Welded

Galvanized Steel Wire Fabric)

ASTM B 209 - Specification for Aluminum and Aluminum Alloy Sheet and

Plate

ASTM D 217 - Test Method for Cone Penetration of Lubricating Grease ASTM D 1056 - Specification for Flexible Cellular Materials - Sponge or

Expanded Rubber

ASTM D 3359- Test Methods for Measuring Adhesion by Tape Test ASTM E-84 - Test Method for Surface Buming Characteristics of Building Materials 


\subsubsection{American Society of Mechanical Engineers (ASME)}

ASME AG-1, Code, Section FC, HEPA Filters

ASME NQA -1 - Quality Assurance Program Requirements for Nuclear

Facilities

\subsubsection{U.S. Product Standards}

APA H850 U.S. Product Standard (PS) for Construction and Industrial Plywood

\subsubsection{Technical Association of the Pulp and Paper (TAPPI)}

T411-OM - Thickness (Caliper) of Paper and Paperboard and Combined Board

T413-OM - Ash in Paper and Paperboard T494-OM- Tensile Breaking Properties of Paper and Paperboard (Using Constant Rate of Elongation Apparatus)

$\mathrm{UM}-440-\mathrm{pH}$ of Paper (cold extract)

\subsubsection{Federal Standards}

FED-STD-141C- Paint, Varnish, Lacquer, and Related Materials; Method of Inspection, Sampling and Testing

2.3.6 Institute of Environmental Sciences, Mt. Prospect, Illinois IES-RP-CC-001.3 - Recommended Practice for HEPA Filters

\subsubsection{Underwriter Laboratories}

UL-586 - Standard for High Efficiency Particulate Air Filter Units 


\section{DOE-STD-3020-97}

Acceptance Test

Inspection and testing of a HEPA filter to verify certain characteristics or properties which determine acceptance or rejection of that filter.

\section{Airflow Resistance}

An index of the energy required to maintain airflow through a filter. Airflow resistance is measured in terms of the air pressure difference (pressure drop) across a filter at a specified flowrate (e.g. see section 5.2.2, Table-1). Note: The initial airflow resistance of a new filter serves as an index of the filter's potential loading capacity.

\section{Approved Test Aerosol}

Particle-generating materials approved by DOE for performance testing. Test aerosols approved by the DOE for tests conducted in the Filter Test Facility are di-octyl phthalate (DOP), also known as DEHP and di-octyl sebacate (DOS), also known as DEHS.

Filter Test Facility (FTF)

A facility established by the DOE specifically to conduct performance quality assurance inspections and tests of HEPA filters.

\section{High Efficiency Particulate Air (HEPA) Filter}

A throwaway, extended-media, dry type filter with a rigid casing enclosing the full depth of the pleats. The filter shall exhibit a minimum efficiency of $99.97 \%$ when tested at an aerosol of 0.3 micrometers diameter. The maximum airflow resistance shall be as specified in Section 5.2, Table 1 of this standard. 


\section{Nominal Air Flow Rating}

The flow rate at which HEPA filters are identified by the manufacturer and confirmed at the FTF. Nominal air flow ratings for various size filters are listed in section 5.2.2, Table 1 of this standard.

\section{Nuclear Facility}

A DOE-owned and operated reactor or non-reactor facility in which radioactive materials are produced or handled to the degree that environmental protection is required.

\section{Penetration}

The downstream test aerosol concentration, expressed as a percentage of the upstream test aerosol concentration.

\section{Preparing Activity}

The DOE organization responsible for issue and interpretation of this standard.

\section{Qualification Test}

A test, often destructive, of a prototype or randomly selected production filter to establish its capability to meet certain functional and specification requirements. The results of the test are considered to typify individual items or model numbers which are of the same design and are manufactured by the same process. 


\subsection{GENERAL REQUIREMENTS}

All HEPA filters to be used for personal or environmental protection purposes in DOE nuclear facilities shall be purchased and tested according to the general requirements of this section (Section 4), and the specific requirements of Sections 5 and 6 of this standard.

4. 1 Prior to use in DOE facilities, filters shall be delivered to a DOE Filter Test Facility (FTF) for acceptance testing.

4. 2 Each filter shall be tested by both the manufacturer and the FTF operator for penetration at $100 \%$ of the nominal airflow rating. Size 3 filters (125 cfm) and greater shall also be tested for penetration at $20 \%$ of the manufacturer's nominal airflow rating (See Section 5.2.2, Table 1 of this standard).

4. 3 All unencapsulated (open faced) HEPA filters shall be tested for airflow resistance at nominal airflow rating. Maximum acceptable resistance for selected filter sizes appear in Section 5.2.2, Table 1 of this standard.

4. 4 HEPA filters which appear on the most recent Military Qualified Products List (QPL), issued 4-10-1995, associated with former Military Specifications MILF-51068, or a corresponding DOE QPL, are considered to meet all the Quality Assurance requirements of Section 6.1 of this standard until their five-year terms expire. The filter medium shall comply with MIL-F-51079.

4.5 HEPA filter media listed on the QPL associated with Military Specification MIL-F-51079 are considered to meet the Quality Assurance requirements of Section 6.1 for filter media only. All other qualification tests specified in Section 6 of this standard shall be performed. 


\subsection{HEPA FILTER PROCUREMENT}

\subsection{General}

HEPA filters to be installed in facilities operated under contract to DOE shall be purchased in compliance with the specifications of this standard. The purchaser shall provide the FTF manager a copy of the purchase order, including any non-standard requirements for the filter product, as a means to assure that the purchase order includes proper specifications, and that the vendor meets the stipulations of the purchase order. Disagreements on the specification content, or changes thereto, shall be resolved in writing by the purchaser and the FTF manager.

\subsection{Performance Requirements}

Mandatory performance requirements for HEPA filters are set out below. These performance requirements must be demonstrated by test or inspection by manufacturer and FTF.

5.2.1 Penetration. Aerosol penetration for any HEPA filter shall not exceed $0.03 \%(0.0003)$ at 0.3 micrometer diameter particles.

5.2.2 Resistance. Air flow resistance across the HEPA filter shall conform to the limits listed in Table 1 below. Tests for resistance to aiflow shall be conducted at flow rates expressed in actual cubic feet per minute (ACFM).

5.2.3 Media Velocity (Effective Media Area). The total effective media area provided within the filter pack shall be such that face velocity shall not exceed $5.0 \mathrm{ft} / \mathrm{min}(1.52 \mathrm{~m} / \mathrm{min})$ at the rated air flow. 


\section{DOE-STD-3020-97}

TABLE 1. Dimensions, Nominal Airflow Ratings, and Maximum

Resistance for typical HEPA Filters ${ }^{a}$

\begin{tabular}{|c|c|c|c|c|c|c|}
\hline \multirow[t]{2}{*}{ Size } & \multirow[t]{2}{*}{$\begin{array}{l}\text { Dimension } \\
\text { in inches }\end{array}$} & \multirow[t]{2}{*}{$\begin{array}{l}\text { Dimension } \\
\text { in millimeters }\end{array}$} & \multicolumn{2}{|c|}{$\begin{array}{c}\text { Nominal Airflow } \\
\text { Rating }\end{array}$} & \multicolumn{2}{|c|}{$\begin{array}{l}\text { Maximum } \\
\text { Resistance }\end{array}$} \\
\hline & & & $\mathrm{cfm}$ & $\mathrm{m}^{3} / \mathrm{hr}$ & in.wg & $\mathrm{Pa}$ \\
\hline 1 & $8 \times 8 \times 3-1 / 16$ & $203 \times 203 \times 78$ & 25 & 42 & 1.3 & 325 \\
\hline 2 & $8 \times 8 \times 5-7 / 8$ & $203 \times 203 \times 149$ & 50 & 85 & 1.3 & 325 \\
\hline 3 & $12 \times 12 \times 5-7 / 8$ & $305 \times 305 \times 149$ & 125 & 212 & 1.3 & 325 \\
\hline 4 & $24 \times 24 \times 5-7 / 8$ & $610 \times 610 \times 149$ & 500 & 850 & 1.0 & 250 \\
\hline 5 & $24 \times 24 \times 11-1 / 2$ & $610 \times 610 \times 292$ & 1000 & 1700 & 1.0 & 250 \\
\hline 6 & $24 \times 24 \times 11-1 / 2$ & $610 \times 610 \times 292$ & 1250 & 2125 & 1.0 & 250 \\
\hline $7^{b, c}$ & $24 \times 24 \times 11-1 / 2$ & $610 \times 610 \times 292$ & 1500 & 2550 & 1.3 & 325 \\
\hline $8^{d}$ & $24 \times 24 \times 11-1 / 2$ & $610 \times 610 \times 292$ & 2000 & 3400 & 1.3 & 325 \\
\hline 9 & $12 \times 12 \times 11-1 / 2$ & $305 \times 305 \times 292$ & 250 & 425 & 1.0 & 250 \\
\hline
\end{tabular}

a Unencapsulated.

${ }^{b}$ Constructed with separators.

c Constructed without separators.

${ }^{a}$ Mini-pleat design.

Note: HEPA filters not listed above (round, rectangular, radial, etc.) which conform to the requirements listed in this standard (5.2 performance requirements, 5.3 materials requirements, and 5.4 filter construction) are acceptable for use at DOE nuclear facilities. 


\subsection{Materials Requirements}

\subsubsection{Filter Media.}

5.3.1.1 Fibrous Filter Media. Non-metallic fibrous filter media shall be procured in compliance with the provisions of MIL-F51079. This shall be cited in the purchaser's specification.

5.3.1.2 Non-fibrous Filter Media. Non-fibrous or metallic filter media are acceptable provided the media meets the applicable specification and performance requirements of Section 6 of this standard and ASME AG-1 Code, Section FC, Mandatory Appendix FC-I. Asbestos is not acceptable as a filter medium component.

\subsubsection{HEPA Filter Case Materials.}

5.3.2.1 Structural Material. Metal filter case material shall be equivalent to USS 14 gage steel as a minimum, with a minimum thickness of 0.0720 inches $(1.8 \mathrm{~mm})$. Wood or wood substitutes are acceptable, provided it can be demonstrated that the filter frame material selected is physically equivalent to plywood specifications which appear in APA H850. Particle board is not acceptable.

5.3.2.2 Fire Retardance. Filter case material shall have a flame spread classification of 25 or less when tested in compliance with ASTM E-84.

5.3.2.3 Hazardous/TSCA/Mixed Waste. Construction materials for HEPA filters shall be selected to avoid generation of EPA regulated wastes as specified in 40 CFR 261 . For this reason, 


\section{DOE-STD-3020-97}

cadmium is no longer acceptable for treatment of filter cases, nor is asbestos acceptable as a HEPA filter component.

\subsubsection{Separator Material.}

5.3.3.1 Asbestos. Asbestos is not authorized as a separator material. (See Section 5.3.2.3, above.)

\subsubsection{Aluminum. Authorized aluminum separator materials are} specified in ASTM B209 as Alloy 1145-H18, Alloy 3003-H19, or Alloy 5052-H38. These separators must have a minimum thickness of $0.00015 \mathrm{in} .(0.038 \mathrm{~mm})$. To protect the filter medium, the separator shall be provided with a "turned edge" prior to corrugation.

\subsubsection{Acid Resistant Separators. Authorized coatings for acid} resistant separators are Teflon, epoxy resin or thermoset vinyl. The coating shall be colored (to identify defects), shall tightly adhere to preclude cracking or delaminating when the material is corrugated, and shall be 0.0001 to 0.0002 in. (2.5 to 5 micrometers) thick (dry film). After corrugation and subsequent flattening, the coating shall exhibit an adhesive peel resistance of $3 A$ or better when tested in accordance with Method A of ASTM D 3359.

5.3.4 Adhesives. Adhesives and sealants, used to seal the filter pack within the filter case and to adhere gaskets to the filter case, shall be nonflammable or self-extinguishing, so that when the dried or cured sealant is subjected to the Spot Flame test of UL-586, it either will not burn, or will not continue to support combustion after the source of combustion has been removed. 
5.3.5 Gaskets and Seals. Two methods are currently employed for sealing the filter to its mounting frame, flat gaskets, and "fluid" seals. The two methods shall not be used on the same mounting frame.

\subsubsection{Flat Gasket. Gasket materials shall be oil and} ozone-resistant, made of synthetic rubber, closed cell sponge Grade $2 \mathrm{C} 3$ or $2 \mathrm{C} 4$ in accordance with ASTM D 1056 , and shall be $1 / 4$ in. $(6 \mathrm{~mm})$ thick by $3 / 4$ in. (19 mm) wide with split or cut surfaces (i.e., no mold skin).

\subsubsection{Fluid Seal. Fluid seals require a specially designed} mounting frame that is not compatible with flat-gasketed sealed filters. The sealant shall be nonflammable as defined in ASTM D092; e.g., no flash at $450^{\circ} \mathrm{F}\left(232^{\circ} \mathrm{C}\right)$ or below; with a fire retardant rating of V-0, per UL-94; hardness, as determined by Brookfield LTV Penetrometer \# 3 , of $0.14-0.24$ in. (3.5-6.0 mm); and allowing no biological growth. Fluid seals must be a non-evaporating, highly viscous, self-healing non-Newtonian substance. The fluid seal substance shall be corrosion resistant, shall not relax, crack, separate, or stick or adhere to the knife-edge, and shall be insoluble in water. The substance shall be thermally stable with a serviceable range of from $40^{\circ} \mathrm{F}$ $\left(4^{\circ} \mathrm{C}\right)$ to $450^{\circ}\left(232^{\circ} \mathrm{C}\right)$. If the fluid seal substance is a grease, the substance shall have a National Lubricating Grease Institute (NLGI) consistency number 2 or 3 as determined by ASTM D 217. Evaporation shall be less than $2 \%$ when tested in accordance with MIL-S-8660C for 24 hours at $390^{\circ} \mathrm{F}\left(198^{\circ} \mathrm{C}\right)$.

5.3.6 Face Guards. Face guards, if required by the filter purchase order, shall be corrosion resistant and nonflammable. 


\section{DOE-STD-3020-97}

\subsection{Filter Construction}

5.4.1 Dimensions. The configuration and dimensions of open face rectangular HEPA filters have been standardized and listed in Section 5.2.2, Table 1 of this standard. All other filter configurations are considered "special" filters whose dimensions and tolerances must be specified in the procurement documents. Dimensional tolerances of "special" HEPA filters should conform to those specified in Section 5.4.3, Table 2 of this standard.

5.4.2 Filter Pack Construction. Filter packs shall be constructed of a continuous sheet of filter medium which shall be pleated evenly to form a pack or panel of equal depth throughout. The filter pack shall be tight when tested according to the method described in Paragraph 8.1 of Institute of Environmental Sciences (IES) Document Number IES-RP-CC-001.3. Repair of pin holes and other defects is not acceptable.

\subsubsection{Pleat and Separator Filters. Separators shall extend at} least $1 / 8 \mathrm{in.}(3 \mathrm{~mm})$ beyond the pleats of filter medium. The plane formed by the edges of the separators shall be at least $1 / 4$ in. $(6 \mathrm{~mm})$ from the plane of the filter frame (less gasket). The pleats shall be straight and shall not deviate more than $1 / 2$ in. (12 $\mathrm{mm}$ ) from a line drawn from one end of the pleat to the other end of the pleat and shall be perpendicular to the filter case.

5.4.2.2 Mini-pleat filters. Filter medium panels shall be sealed in a reservoir which is at least $1 / 16$ in. $(1.6 \mathrm{~mm})$ deep. The panels shall not vary more than $1 / 2 \mathrm{in.}(12 \mathrm{~mm})$ from a line drawn from the top to the bottom of the panel and perpendicular to the case. Filter medium support (ribbons, strings, etc.) shall not vary more than $1 / 2$ in $(12 \mathrm{~mm})$ from a straight line drawn from top to bottom of the line formed by the supports and shall be perpendicular to 


\section{DOE-STD-3020-97}

the case. The filter medium support shall be nonflammable. The panels on the left and right sides of the filter shall be sealed to the case with adhesive.

\subsubsection{Separatorless Filters. Dividers shall be provided as} appropriate for additional support. The vertical plane formed by the ends of the convolutions shall not deviate more $3 / 4$ in. (19 mm) from the top to bottom of the pleat and shall be recessed at least $1 / 16 \mathrm{in} .(1.6 \mathrm{~mm})$ from the plane formed by the four sides of the filter frame. Where convolutions do not have crest-to-crest contact, spacing shall not be less than $1 / 16$ in. $(1.6 \mathrm{~mm})$. Nesting of convolutions is not permitted. Abrupt kinks or deviations in the folds of the medium are not permitted. The trimmed edges of the filter element shall be firmly potted (fixed) into the sealant. The two flap edges shall have sufficient sealant to secure them to the frame sides.

\subsubsection{Filter Case. The case shall be fabricated in compliance with the} provisions of Section 5.3.2 of this standard. The completed case, less gaskets, shall conform to the dimensions listed in Section 5.2.2, Table 1 of this standard, unless alternative dimensions are specified in procurement documents. Section 5.4.3, Table 2 of this standard lists the acceptable tolerances. 
TABLE 2. Tolerances for Filter Cases

a. Face Dimensions:

i. less than $18 \mathrm{in} . \quad+0,-1 / 16$ in. $(1.6 \mathrm{~mm})$

$(45.7 \mathrm{~cm})$

ii. greater than 18 in. $\quad+0,-1 / 8$ in. $(3 \mathrm{~mm})$

$(45.7 \mathrm{~cm})$

b. Depth: $\quad+1 / 16$ in. $(1.6 \mathrm{~mm}),-0$

c. Width of gasket surface: $3 / 4 \mathrm{in} .(19 \mathrm{~mm}) \pm 1 / 16 \mathrm{in} .(1.6 \mathrm{~mm})$

d. Squareness: face diagonals to be equal with the following total tolerances.

i. less than $18 \mathrm{in.} \quad 1 / 16 \mathrm{in}$. total $(1.6 \mathrm{~mm})$

$(45.7 \mathrm{~cm})$

ii. greater than $18 \mathrm{in.} \quad 1 / 8 \mathrm{in}$. total $(3 \mathrm{~mm})$

$(45.7 \mathrm{~cm})$

e. Gasket seating surfaces: Square with sides of frame (within $3^{\circ}$ ). flat and parallel.

$1 / 16$ in. $(1.6 \mathrm{~mm})$ total allowance when measured with one face of the filter resting on a flat surface.

5.4.3.1 Wooden Cases. Case panels shall be joined with rabetted joints which are assembled by gluing with an adhesive meeting the requirements of Section 5.3.4 of this standard and double nailing or double screwing with coated box nails, corrosion resistant plated screw-nails, or flathead wood screws. The end points of the fasteners shall not penetrate the inside or outside surfaces of the case. Frame faces, edges, and inner surfaces shall be thoroughly coated with sealant to minimize permeability. Frame face sealant shall not reduce the ability of the gasket to adhere to the frame. There shall be no splinters or rough edges that might penetrate or cut workers' gloves or injure the fingers of personnel handling the filters. 
5.4.3.2 Metal Cases. Metal cases shall have a double-turned, $3 / 4 \mathrm{in}$. $(19 \mathrm{~mm})$ wide flange on each face or a fluid-seal socket or sleeve as specified in the procurement documents. Panels shall be assembled into the frame by riveting or bolting the comers, or by potting a subassembly consisting of the filter pack and side panels into the top and bottom panels (but not the comers), using an adhesive meeting the requirements of Section 5.3.4 of this standard. For mechanically joined panels the space between abutting panels shall be sealed with an adhesive meeting the requirements of Section 5.3.4 of this standard.

5.4.5 Gaskets. Gaskets shall be glued firmly and continuously to the case. Loose, peeling, or distorted gaskets shall be cause for rejection of the filter. The gasket shall not extend more than 1/16 Êin. (1.6 mm) over either side of the seating surface at any point. Gaskets may be of one-piece or made up of strips joined at the corners by keyhole, keystone, or other interlocking type joints. Edges of the joint area shall be thoroughly coated with adhesive (sealant meeting requirement of Section 5.3 .4 of this standard) before assembly.

5.4.6 Faceguards. Faceguard edges shall be firmly embedded in adhesive and shall be installed so that projecting wires or edges do not form a puncture hazard to personnel handling the filter and do not project onto or beyond the gasket mounting surface. Wire edges formed when slitting or shearing expanded-metal faceguards shall be smoothed on both surfaces of the material before installation. 


\subsection{QUALITY ASSURANCE}

\subsection{Manufacturer's Quality Assurance Program, Procedures, and Documentation}

Filters shall be manufactured and shipped under a quality assurance program meeting the essential requirements of ASME NQA-1.

Procurement and fabrication activities shall allow positive identification of the grades of source materials used in construction, and permit positive identification of the roll (or production run for separatoriess filters) of filter medium used in the completed filter. All tests and inspections shall be conducted in accordance with documented manufacturer's procedures, and the results shall be traceable to specific lots of completed filters. The results of penetration and resistance tests specified in Section 6.2 of this standard shall be documented and identified by serial number for each individual filter unit. Nonconformances with the above items and documentation of problems and their resolution shall be addressed in the manufacturer's QA Plan.

6.1.1 Qualification. Filter manufacturers shall be required to show evidence that HEPA filters meet the test requirements of Sections 6.1 .3 to 6.1 .5 of this standard.

Qualifications testing must be performed and certified by an independent test laboratory.

Requalification is required every five years.

If a filter fails any or all of the qualifications tests, the test organization shall first notify the manufacturer, and provide the manufacturer the opportunity to review test methods and results prior, to removing the filter model from the QPL. (or similar qualifications list) and issuing notice thereof. 


\section{DOE-STD-3020-97}

In order to reduce costs associated with qualification testing, successful tests of filters with known material components for filter frames, filter medium, cases and adhesives, produced by a single manufacturer, can be used to qualify filters of similar construction, but smaller sizes by the same manufacturer. Tests of:

- Filter Size 5 shall qualify similar filters of sizes 1 through 5 .

- Filter size 6 shall qualify similar filters of sizes 1 through 6.

- Filter Size 7 shall qualify similar filters of sizes 1 through 7 .

- Filter Size 8 shall qualify similar filters of sizes 1 through 8 .

DOE reserves the right to randomly select HEPA filters from existing storage at DOE sites and perform the tests defined in Sections 6.1.3 through 6.1 .5 of this standard. If failures are noted, procurement organizations shall be notified that the failed filter model has been removed from the current DOE QPL. The manufacturer, the DOE FTF, and DOE contractor procurement specialists shall be informed that the failed filter model is no longer acceptable for use at DOE facilities, pending requalification.

\subsubsection{Qualifications Testing. Qualifications tests of filter components shall} be conducted in accordance with requirements of Sections 6.1.3 through 6.1 .5 of this standard and applicable specification and performance requirements of ASME AG-1. If a manufacturer's filter model, consisting of a specific set of components including frame, adhesive, and filter medium, is listed in a current QPL, this shall constitute satisfactory evidence of having met the qualification requirements of this standard. Filters selected for qualification testing may be prototypes of the proposed design or production filters of the specific design randomly selected from the manufacturer's stock. The number of filter units required for qualification testing shall be as specified in ASME AG-1. Modification of these requirements shall be only as specified below. 
6.1.3 Overpressure Resistance. The new, unused filter, when preconditioned according to ASME AG-1 Code, Section FC, Section 5140, "Resistance to Pressure," shall withstand a pressure differential of $10 \pm 0.2$ in. wg $(2500 \pm 50 \mathrm{~Pa})$ for 60 minutes without visible evidence of damage. Within 15 minutes of the pressure differential test, and while still wet, the filter shall meet the penetration requirement of Section 6.2 .2 at $20 \%$ of nominal airflow rating (size 4 and larger filters).

6.1.4 Resistance to Fire and Heated Air. The new, unused filter shall withstand exposure to air heated to $700_{j} F \pm 50_{j} F\left(370_{j} \hat{E} \pm \hat{E} 28_{j} C\right)$ for 5 minutes. After exposure to heat, the penetration, when tested at nominal airflow rating, shall not exceed $3.0 \%$. There shall be no evidence of sustained buming when subjected to a spot flame at any point on the filter except the gasket. Labeling or certification (by Underwriters Laboratories) in accordance with UL-586 shall provide evidence of satisfactory compliance with applicable requirements for resistance to fire and heated air.

6.1.5 Resistance to Rough Handling. The filter shall withstand shaking for 15 minutes at 3/4-in. ( $19 \mathrm{~mm}$ ) amplitude and 200 cycles per minute $(3.33 \mathrm{~Hz})$ without evidence of filter damage. The test shall be conducted with the filters boxed, and the pleats and separators vertical. After the test, the filter shall meet the penetration requirement of Section 6.2 .2 of this standard at $100 \%$ (all filters) and $20 \%\left(125 \mathrm{cfm}\left[212 \mathrm{~m}^{3} / \mathrm{hr}\right]\right.$ and larger) at the nominal airflow rating.

\subsection{DOE Production Testing and Marking}

\subsubsection{Acceptance Inspection and Testing. Prior to installation at a DOE} site, each HEPA filter shall be tested at a DOE FTF. Acceptance is contingent upon satisfactory completion of inspections and tests specified in DOE Standards. Filters will be inspected for physical damage to the packaging and filter, and for compliance with specification requirements which can be checked visually. Each filter 
shall be tested for penetration and resistance. The penetration at each specified airflow and the resistance at nominal airflow rating shall be marked clearly and indelibly on the case of the filter unit tested. At the discretion of the FTF, the customer may be advised to request the manufacturer to supply evidence of compliance with qualifications tests and materials requirements of the specification. Failure to meet inspection, test, or verification requirements shall be cause for rejection of the filter(s). After the testing and inspection is completed, each filter will bear a FTF test label indicating acceptance or rejection.

\subsubsection{Penetration. Each filter unit shall be tested for penetration by a} DOE-approved aerosol and test method at a DOE FTF as follows:

- Size 1 and 2 (up to $125 \mathrm{cfm}$ [212 $\left.\mathrm{m}^{3} / \mathrm{hr}\right]$ ) filter units: $100 \%$ of rated airflow.

- Size $3\left(125 \mathrm{cfm}\right.$ [212 $\left.\left.\mathrm{m}^{3} / \mathrm{hr}\right]\right)$ and larger filter units: $100 \%$ and $20 \%$ of rated aiflow.

- Filters with penetration rates in excess of $0.03 \%(0.0003)$ measured at a particle diameter of 0.3 micrometer shall be rejected. When tested with a laser spectrometer test method, the maximum penetration and the aerosol particle size of maximum penetration shall be reported in addition to the penetration at 0.3 micrometers diameter. However, penetration at 0.3 micrometers diameter shall be the only criterion used to judge whether a filter is rejected for excess penetration.

6.2.3 Resistance. The air flow resistance across the HEPA filters shall conform to the limits listed in Section 5.2, Table 1. Tests for resistance to airflow shall be conducted at flow rates expressed in actual cubic feet per minute (ACFM). 
6.2.4 Accepted and Rejected Filters. Accepted filters shall be marked as specified in DOE standards.

\subsection{PACKAGING, SHIPPING, AND STORAGE}

\subsection{Packaging and Shipping for Testing}

7.1.1 Packaging. HEPA filters shall be packed in individual, durable containers which meet applicable shipping regulations.

7.1.2 Preparation for Delivery. The contractor's shipping instructions shall specify that HEPA filter cartons be crated or placed on a pallet to minimize unit handling, particularly at public carrier interchange points. Filters should not be stacked more than three (3) high. For large shipments, it is recommended that the entire shipment be shipped in a sealed, dedicated trailer or rail car. At all times the filters must be handled with care and properly orientated.

7.1.3 Packaging. Shipping and Storage. Packaging, shipping and storage shall be in accordance with NQA-2, level B.

\subsection{Shipping}

HEPA filters to be tested shall be shipped to the address below, as agreed to by the procurement specialist and the vendor.

1) Lockheed Martin Energy Systems

K-25 Site, Building K-1024

Oak Ridge, Tennessee 37830

Attention: Filter Test Facility 


\section{DOE-STD-3020-97}

\subsection{Reshipment}

Following satisfactory completion of inspections and tests specified in section 6.2 of this standard, the FTF will repack the tested filters in a manner comparable to the received packaging, and forward them to the address specified by the customer.

\subsection{Rejected Filters}

Rejected filters will be disposed of by the FTF in accordance with written instructions on file from the purchaser and/or the manufacturer. 
DOE-STD-3020-97

Intentionally Blank 
CONCLUDING MATERIAL

Review Activity:

Preparing Activity:

DOE-DP-45

DOE
DP
$E E$
$E H$
$E M$
$E R$
$F M$
$G C$
$H R$
IG
$N E$
$R W$

Field Offices

Albuguerque Operations Office

Chicago Operations Office

Idaho Operations Office

Project Number:

Nevada Operations Office

FSC-4460-0005

Oakland Operations Office

Oak Ridge Operations Office

Rocky Flats Office

Richland Operations Office

Savannah River Operations Office

National Laboratories

Brookhaven National Laboratory

Los Alamos National Laboratory

Lawrence Livermore National Laboratory

Oak Ridge National Laboratory

Sandia National Laboratory

Power Authorities

WAPA 
DOE F 1300.3

(01-94)
U.S. DEPARTMENT OF ENERGY

DOCUMENT IMPROVEMENT PROPOSAL.

(Instructions on Reverse)
OMB Control No

$1910-0900$

OMB Burden Disciosure

Statement on Reverse

Document Number

2. Document Title

3a. Name of Submitting Organization

4. Type of Organization (Mark one)

$\square$ Vendor

User

3b. Address (Street, City, Zip Code)

Manufacturer

$\square$ Other (Specify:

5. Problem Areas (Attach extra sheets as needed.)

a. Paragraph Number and Wording

b. Recommended Wording

Reason/Rationale for Recommendation

6. Remarks

7a. Name of Submitter (Last, First, MI)

7b. Work Telephone Number (Include Area Code)

7c. Mailing Address (Street, City, State, Zip Code)

8. Date of Submission 
INSTRUCTIONS: In a continuing effort to improve the U.S. Department of Energy (DOE) Technical Standards, this form is provided for use in submitting comments and suggestions for improvements. All users of DOE Technical Standards are invited to provide suggestions. This form may be detached, folded along the lines indicated, taped along the loose edge (DO NOT STAPLE) mailed to the address indicated or faxed to (423) 574-0382.

1. The submitter of this form must complete blocks 1 through 8.

2. The Technical Standards Program Office (TSPO) will forward this form to the Preparing Activity. The Preparing Activity will reply to the submitter within 30 calendar days of receipt from the TSPO.

NOTE: This form may not be used to request copies of documents, nor to request waivers, deviations, or clarification of specification requirements on current contractors. Comments submitted on this form do not constitute or imply authorization to waive any portion of the referenced document(s) or to amend contractual requirements.

\title{
OMB Burden Disciosure Statement
}

Public reporting burden for this collection of information is estimated to average 30 minutes per response, including the time for reviewing instructions, searching existing data sources, gathering and maintaining the data needed, and completing and reviewing the collection of information. Send comments regarding this burden estimate or any other aspect of this collection of information, including suggestions for reducing this burden, to Office of Information Resources Management Policy, Plans, and Oversight, Records Management Division, HR-422 - GTN, Paperwork Reduction Project (1910-0900), U.S. Department of Energy, 1000 Independence Avenue, S.W., Washington, DC 20585; and to the Office of Management and Budget (OMB), Paperwork Reduction Project (1910-0900), Washington, DC 20503.

\author{
U.S. Department of Energy Technical Standards Program Office \\ c/o Performance Assurance Project Office \\ P.O. Box 2009, Bldg. 9201-3 \\ Oak Ridge, Tennessee 37831-8065
}

